\title{
USING TERRESTRIAL LASER SCANNING AND LIDAR DATA FOR PHOTO-REALISTIC VISUALISATION OF CLIMATE IMPACTS AT HERITAGE SITES
}

\author{
A. Nettley ${ }^{\text {a }}{ }^{*}$, K. Anderson ${ }^{a}$, C. DeSilvey ${ }^{\text {a }}$, C. Caseldine ${ }^{\text {a }}$, \\ ${ }^{a}$ Department of Geography, College of Life and Environmental Sciences, Tremough Campus, Penryn, Cornwall, UK
}

KEY WORDS: terrestrial laser scanning, heritage, 3D visualisation, photo-realism, community, sea-level rise, climate change

\begin{abstract}
:
Remote sensing technologies such as terrestrial laser scanning (TLS) and light detection and ranging (LIDAR) can now provide accurate spatial data for describing topographic patterns in landscapes and mapping the fine geometric detail of complex structures. Interdisciplinary studies using such data for characterising heritage sites are now widespread, but it is less common for data derived from these technologies to be used in an operational setting to 'engage' local people with the idea of future change. Threedimensional landscape models using TLS and LIDAR are a powerful way of communicating climate change to lay audiences on a local level and the use of multi-scale spatial data can help to show the anticipated impacts of climate change at heritage sites. The aim of this paper is to present the results of a project designed to produce a photorealistic geospatial model of the historic quayside at Cotehele Quay, Cornwall, UK. Our central aim was to generate a spatially accurate and visually realistic three-dimensional model of the site for use in local engagement strategies. TLS and LIDAR data were collected and processed to produce a three-dimensional model. The key image processing stages included: registration to a national co-ordinate system, meshing using 3D reshaper and visualisation creation in 3DS Max. The resulting model will permit spatial consideration of the impact of management strategies at the site. The over-arching application of this method beyond the study site will provide a platform for discussion that addresses the needs of site managers and the expectations of local communities.
\end{abstract}

\section{INTRODUCTION}

This paper gives a detailed insight into the methods used to generate a 3-dimensional (3D) photo-realistic visualisation of a coastal heritage site regularly affected by flooding. It will consider the processing stages required to generate a visually 'realistic' model while maintaining accuracy in data.

\subsection{Climate Change}

In the UK one of the largest threats from future climate change is anthropogenically-driven sea-level rise, which is predicted to have a measurable impact on much of the UK coastline (Jenkins, Murphy et al. 2009). The UK is faced with the prospect of between 180 to $590 \mathrm{~mm}$ of sea level rise (SLR) by 2100 (IPCC 2007). As a result, many coastal regions of the UK will suffer increased rates of coastal erosion, and local authorities are taking action to develop adaptation strategies which will mitigate the impacts in the long and short term (e.g. Pathfinder Projects (DEFRA 2010). Although the most comprehensive predictions about climate change are produced on a global or continental scale (IPCC 2007), there is scientific recognition that most of the effects will be felt by individuals on a local level, and there is a growing need to address policy decisions at this scale (Adger, Arnell et al. 2005). This project is focused on using spatial data acquired by laser scanning techniques at two scales (airborne and terrestrial). These techniques provide both fine spatial resolution data deserved of a heritage site, and a landscape-extent LIDAR data digital surface model to enable the wider context to be considered.

\subsection{Heritage Context}

A consensus is building which supports the need for educating the public on the impact of climate change on cultural heritage and the historic environment (Cassar et al, 2005; Brenner et al, 2008; Cassar, 2005). Because sites of heritage have an intangible value as places of memory (Ahmed 2006), as well as a historical value linked to the presence of cultural artefacts, it is important to discuss with affected people the projected impacts of climate change, and the need for a long-term view in planning and management. Flatman (2009) has identified in the UK public a lack of understanding about how heritage structures have responded to climate over time. Research by the Centre for Sustainable Heritage (Cassar 2005) also suggests that there is need to investigate the forces which disrupt the equilibrium of a site both incrementally and abruptly. Management still tends to wait for an extreme event, which shows clear impacts, rather than record and respond to everyday effects. Heritage managers, however, are beginning to plan for an adaptive, extended response to climate change impacts, and have recognised the need for local level communication and consultation in this process.

The National Trust (NT) is responsible for 700 miles of UK coastline, with $279 \mathrm{~km}$ threatened from increased coastal erosion and tidal flooding in the South West of the UK alone (National Trust 2005). Much of this coastline is protected and managed for its heritage value, yet the NT recognises that it may not be economically or physically possible to continue to protect all of its coastal cultural heritage properties given the increasing impacts of sea-level rise and intense storm activity

\footnotetext{
*ajn203@exeter.ac.uk
} 
Recognition that a long-term perspective may mean adapting to, rather than defending against, coastal change was made by the NT in 2005 with the publication of their Shifting Shores document (National Trust 2005). The document identified that long-term adaptive management which 'works with nature' (National Trust 2005) was the only way to balance future social, economic and environmental demands at their coastal properties. The adoption of this coastal management policy sits uneasily with the NT's promise to protect the places in their care "forever, for everyone" (National Trust 2010, DeSilvey In press). Since 2005, the NT has been developing communication strategies that take into account emotional attachments to threatened places (Tunbridge and Ashworth 1996) and help people to understand and adapt to projected changes to heritage environments.

\subsection{Tamar Valley and Cotehele Quay}

The Tamar Valley is situated on the border between Devon and Cornwall and is protected as an Area of Outstanding Natural Beauty (AONB). Natural England has identified the lower Tamar River and Valley as requiring higher level stewardship (HLS), which further justifies its environmental value. Furthermore, Natural England has highlighted the significant value of this region for its coastal habitats, historic parklands and historic buildings (Natural England, 2008). Adaptation strategies vary at different locations, and in the Tamar Valley the complex interaction between natural habitats and the historic built environment has meant that other coastal adaptation strategies (such as that implemented at Porlock Bay, Somerset) have not adequately dealt with the issues raised at this site where there are conflicts between landscapes and the built environment.

Cotehele $\left(\mathrm{N} 50^{\circ} 29.30, \mathrm{~W}^{\circ}{ }^{13.22}\right)$ is a National Trust property situated on the River Tamar consisting of two unique heritage features, Cotehele House and Cotehele Quay. The latter is the primary focus for this study. Cotehele Quay is situated at $2.5 \mathrm{~m}$ above sea level on an estuarine site in the Mid-Tamar Valley. It is affected by a tidal ranges varying from 0.4 to 4.6 metres on spring tides. The historic quayside was a busy port at the peak of the Cornish mining industry (circa 1850-1905) and is recognised as being of considerable heritage value, as demonstrated by its inclusion in the Cornwall and West Devon Mining Landscape World Heritage Site (designated by UNESCO in 2006). The quay incorporates features of historic interest, including lime kilns, barns, maritime artefacts and the stone-built quayside itself. The Environment Agency's first Shoreline Management Plan document (1995) identified significant risks at Cotehele Quay, anticipating a short term increase in the frequency of flooding to the quayside and adjacent buildings, with more severe effects in the medium to long term (10+ years) (CCPL 1995).

\subsection{Aims}

Although the applications and uses for TLS data in 3D visualisation have been widely explored in the literature (Zhilin et al., 2008), this paper looks to develop a more thorough workflow for the production of $3 \mathrm{D}$ visualisations which can be used to engage people with planning for adaptation at heritage sites. The aims of this paper are:

- To present a workflow for the generation of 3D visualisations

- To discuss the relationship between realism and accuracy in $3 \mathrm{D}$ visualisation
- To suggest a method for communicating the impacts of climate change using animation software

\section{DATA ACQUISITION}

This paper presents a workflow for the generation of 3D visualisations, through data acquisition to processing and animation. The workflow has been developed with the intention that this method could be transferable to other sites.

\subsection{Terrestrial Laser Scanning}

A TLS system is "any ground based device that uses a laser to measure the three-dimensional coordinates of a given region of an object's surface automatically, in a systematic order at a high rate in (near) real time" (Barber et al., 2003: 622). The data collected are more commonly known as a 'point cloud', a common co-ordinate system in which each data point has an $\mathrm{X}, \mathrm{Y}, \mathrm{Z}$ value as well as an intensity value (Barber 2003). Scanning was carried out at Cotehele Quay in 2010, using a Leica HDS 3000 pulse-based (time-of-flight) measuring device over three days [Fig. 1].

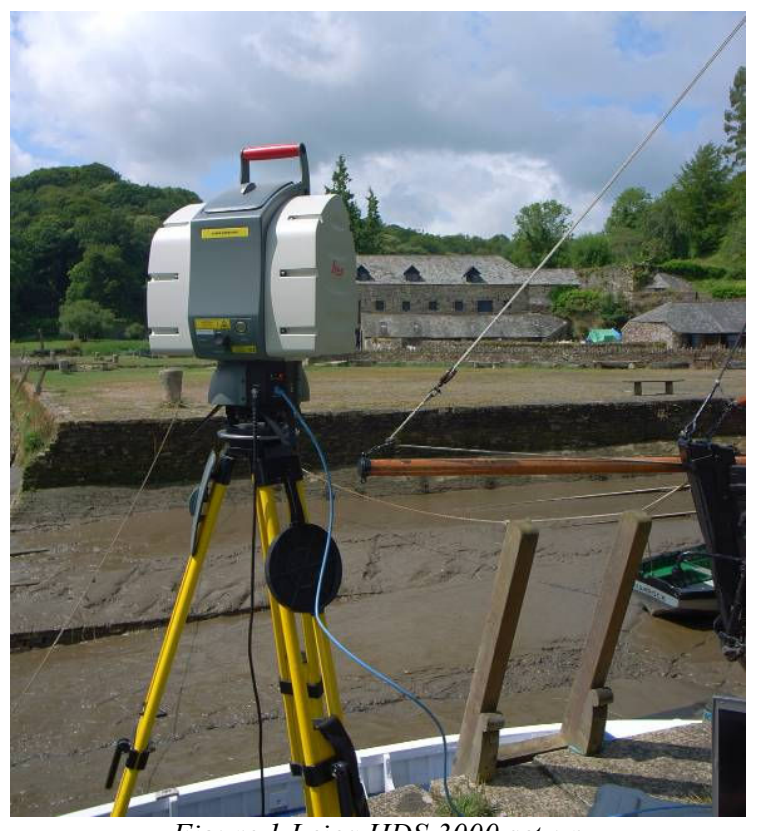

Figure 1 Leica HDS 3000 set-up

The various scanning positions of the TLS were determined following an initial site visit. These were chosen so as to capture data about as large a spatial extent as possible. Over three days 13 scan locations were used to capture selected areas of the site [Fig 2]. At each location set-up either one or two scans were carried out; these included $360^{\circ}$ horizontal rotations of the scanner at three locations with varying vertical angles. A total of over 9 million data points were recorded in 21 "scan worlds".

The accuracy of individual recorded data points varies and is affected by range (the distance from the laser to the observed object) and also by the intensity of the reflected laser pulse (Schulz and Ingensand 2004). Therefore increases in the distance between scanner and object, and decreases in the reflectivity of the measured object reduce the accuracy of the point recorded. The accuracy of the HDS 3000 scan system is detailed in Table 1. It should be noted that these statistics do not account for a reduction in data accuracy for low-reflective 
surfaces. During scanning at Cotehele Quay the average range for all measurements was below $50 \mathrm{~m}$, and based on the product specifications [Table 1] it can be assumed that accuracy was maintained below $6 \mathrm{~mm}$ for points recorded within this range.

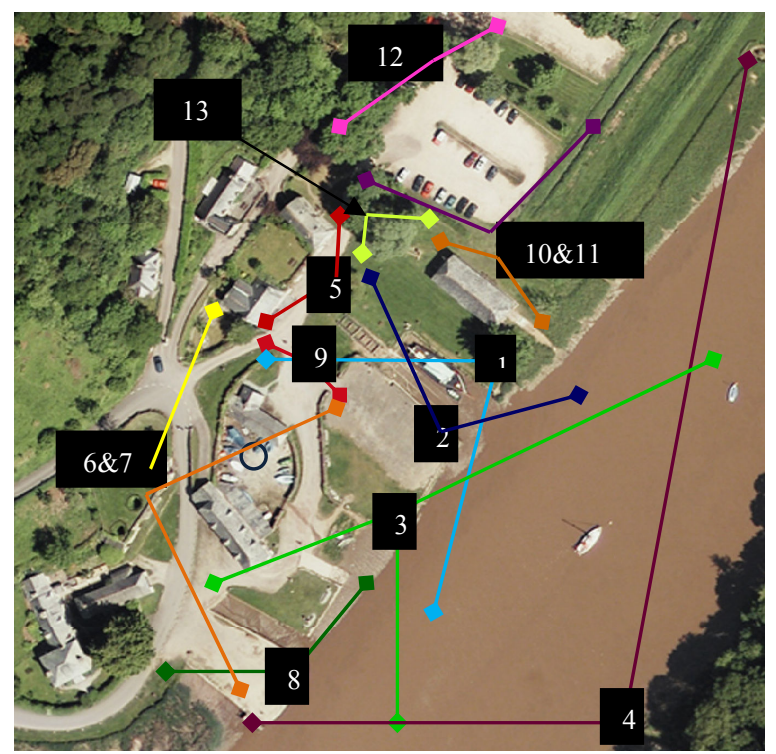

Figure 2 Location of scan stations

\begin{tabular}{|l|l|}
\hline $\begin{array}{l}\text { Accuracy of single } \\
\text { measurement }\end{array}$ & \\
Position* & $6 \mathrm{~mm}$ \\
Distance* & $4 \mathrm{~mm}$ \\
Angle (horizontal / vertical) & 60 microradians, $+/-1 \mathrm{SD}$ \\
\hline $\begin{array}{l}\text { Modelled surface precision / } \\
\text { noise }\end{array}$ & $2 \mathrm{~mm},+/-1 \mathrm{SD}$ \\
\hline Target acquisition & $2 \mathrm{~mm}+/-1 \mathrm{SD}$ \\
\hline
\end{tabular}

Table 1 Accuracy specifications Leica HDS 3000 (Leica 2010) *@ $1 m-50 m$ range

\subsubsection{Spatial resolution}

The resolution of the landscape model needs to be at least an order of magnitude, greater than the sampling density of the most detailed scan feature (Nagihara, Mulligan et al. 2004). On the first visit, scans were carried out with differing settings (in Cyclone, version 5.4, Leica Geosystems) for the spatial resolution. Scans were carried at with point spacings of $10 \mathrm{~mm}$, $25 \mathrm{~mm}$ and $100 \mathrm{~mm}$ at a $50 \mathrm{~m}$ range. This was done to capture detail on particular objects of interest. However, it was realised that in order to maintain consistency of the dataset this should be standardised. The completion of scanning at the site for the following 2 days was carried out at a point spacing of $25 \mathrm{~mm}$ at an average range of $50 \mathrm{~m}$. As data were collected, the field of view (FOV) for neighbouring scans created overlap regions, yielding multiple coverage of most areas within the site. This enabled accurate co-registration of scans using objects that appeared in $>1$ scan world, and additionally produced a dataset with an overall more densely sampled point cloud than suggested by the $25 \mathrm{~mm}$ spacing of a single scan. Leica's Cyclone software was used to register the 21 scan worlds together into a single TLS model of the entire quayside site. The results of this process are discussed in Section 3. Other datasets were then required in order to render this point cloud useable in a geographical sense. These datasets are described in the subsequent sections.

\subsection{DGPS Survey}

The next stage in the processing was to gather data in the field for registration of the point cloud data to the British National Grid. To achieve this, a differential GPS base station was first set-up at Cotehele (located at N50 29.6898, W $^{\circ}{ }^{\circ} 13.5487$ ) and left for 2 hours to collect data. Using receiver independent exchange format (RINEX) software differential corrections were made using the nearest UK Ordnance Survey vector difference corrections following the method described in Anderson et al, (2010). Upon returning to the site the base station was set-up with the determined DGPS co-ordinates. A pole-mounted roving DGPS receiver (HiPER Pro, Topcon) was then used to survey of the rest of the site against the determined base station position. The reported accuracies of the roving system were $<10 \mathrm{~mm}$ (horizontal) and $<15 \mathrm{~mm}$ (vertical; Topcon 2009 in Anderson et al., 2010). Key features describing the geometry of the site, such as corners of buildings and stone work, were collected with the roving receiver. Around 80 individual co-ordinates were collected with six of these being used in Cyclone to register the point cloud to the British National Grid.

\subsection{LIDAR}

LIDAR data collected by the UK Environment Agency from the Lower and Mid Tamar Valley Area were used to provide a regional perspective of the topography. The data used in this project were free to access through an online repository called the Channel Coastal Observatory (http://www.channelcoast.org/). These data had a spatial resolution of 2 metres. The digital surface model (DSM) generated from these data was used to place Cotehele in the broader geographical context.

\subsection{Aerial Photo Imagery}

High resolution aerial photography was also collected over the study site. The aerial photo archive covered $4 \mathrm{~km}^{2}$ over Cotehele House and Quay, and the surrounding area. The images were extracts from the Millennium Map Project, (CGetmapping PLC). These images were used in the later stages of the used to texture the LIDAR data, a process which is discussed later in this paper.

\section{3D MODELLING}

Although animation and computer aided design (CAD) software programmes are not able to process effectively the amount of data points produced from TLS, it was still necessary to scan the site at a fine spatial resolution. The intermediary processing stage of transforming the points to a polygonal mesh requires a dense point cloud in order to optimise the closeness match between points and mesh (explored further in section 3.2). The following sections will describe how the data from the dense TLS point cloud were processed to maximise information extraction while also maintaining the geometric qualities of the data to maximise the realistic representation of landscape features.

\subsection{Registration of 21 scan worlds using Leica's Cyclone software}

The TLS were registered in Leica's Cyclone software using the geometric tie-points of the site. In total 21 scans were registered and geo-rectified using DGPS data from the ground-based 
DGPS survey. The root mean square error (RMSE) generated during registration of each scan pair varied [Table 2]. There was no correlation between the number of points in a scan world and the accuracy of the resultant registration. As the size of the complete point cloud increased, the RMSE decreased [Table 2]. The unified and registered dataset was exported in several formats, .xyz, .pts and .dxf. The buildings on site, including the museum, lime kilns, restaurant and workshop were exported as individual files because these were required at different mesh resolutions in order to maintain their geometric consistency and to maintain representativeness to their real-world structures. Subsequent processing stages sought to refine the various point cloud models resulting from (consisting of $>9$ million individual scan points) into a useful spatial dataset for use in the visualisation.

\begin{tabular}{|l|l|l|}
\hline $\begin{array}{l}\text { Registration } \\
\text { scanworlds }\end{array}$ & $\begin{array}{l}\text { Overlap point } \\
\text { count }\end{array}$ & Error statistics \\
\hline $1 \& 2$ & 554166 & $\begin{array}{l}\text { RMS }=0.0101 \mathrm{~m} \\
\text { Avg }=0.0067 \mathrm{~m}\end{array}$ \\
\hline $5 \& 6$ & 104833 & $\begin{array}{l}\text { RMS }=0.0230 \mathrm{~m} \\
\text { Avg }=0.0154 \mathrm{~m}\end{array}$ \\
\hline $1,2,3 \& 4$ & 180766 & $\begin{array}{l}\text { RMS }=0.0258 \mathrm{~m} \\
\text { Avg }=0.0187 \mathrm{~m}\end{array}$ \\
\hline ALL & 1683833 & $\begin{array}{l}\text { RMS }=0.0093 \mathrm{~m} \\
\text { Avg }=0.0035 \mathrm{~m}\end{array}$ \\
\hline
\end{tabular}

Table 2 Example error statistics; RMS (root mean square), Avg (average)

\subsection{Meshing the point cloud using 3D Reshaper}

To generate a mesh of the point cloud, graphical analysis software (3D Reshaper; Technodigit, France) was used. This software is able to handle the large number of points generated by TLS and a mesh can be created which closely matches the original data. It was found that the most easily compatible file type to import into 3D Reshaper was the .pts format; this is a simple graphics file that commonly holds $3 \mathrm{D}$ point locations. The separation of the site into 'terrain' (the natural topography of the site) and buildings meant that these could be meshed at varying densities, an important step to take when modelling both natural and man-made features. As a consideration, increasing the number of polygons in the mesh will improve accuracy, by reducing the standard deviation of interpolated points. 3D Reshaper is limited to the number of polygons it can effectively handle without using all the available computer memory $(\sim 200,000$ polygons on a system $2.93 \mathrm{GHz}, 2 \mathrm{~GB}$ RAM). However, mesh optimization can reduce the density of the mesh whilst maintaining edges and features [Fig. 3].

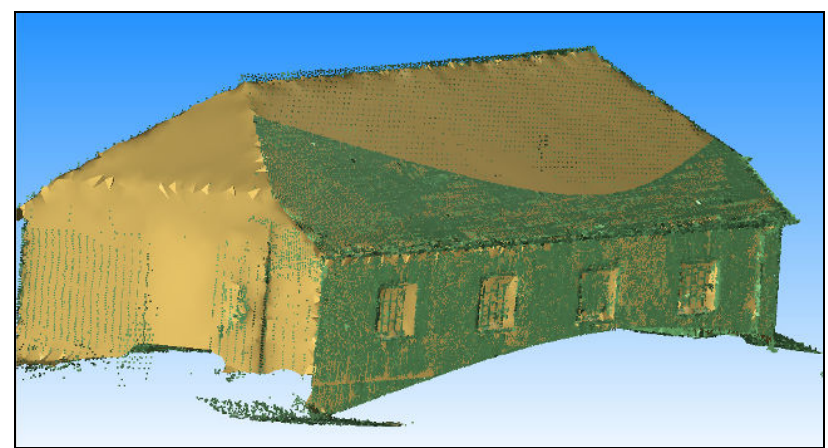

Figure 3 A comparison of mesh and original point data; yellow: mesh generated by $3 D$ Reshaper, green: original point data
Table 3 shows the resultant mesh sizes for each component of the site.

\begin{tabular}{|l|l|l|}
\hline Object & $\begin{array}{l}\text { Mesh size: before } \\
\text { (\# polygon faces) }\end{array}$ & $\begin{array}{l}\text { Mesh size: } \\
\text { reduced (\%) }\end{array}$ \\
\hline Workshop & 88626 & $9868(89 \%)$ \\
\hline Discovery Centre & 165783 & $87803(47 \%)$ \\
\hline Lime Kiln/Garage & $8530 / 2373$ & $\begin{array}{l}8530 / 2373 \text { (not } \\
\text { reduced) }\end{array}$ \\
\hline Edgcumbe Arms & 131328 & $237(99 \%)$ \\
\hline Shop Block & 100901 & $\begin{array}{l}100901(\text { not } \\
\text { reduced) }\end{array}$ \\
\hline Terrain & 211983 & $156199(27 \%)$ \\
\hline LIDAR & 49923 & $\begin{array}{l}49923 \text { (not } \\
\text { reduced) }\end{array}$ \\
\hline
\end{tabular}

Table 3 Mesh densities (in number of polygon faces) for each object; $3 D$ Rehshaper and reduced mesh size with percentage lost

\section{VISUALISATION}

One can define a visualisation as being "concerned with exploring data and information in such a way as to gain understanding and insight into the data [...] and to foster new insight into the underlying processes, relying on the humans' powerful ability to visualise" (Earnshaw and Wiseman 1992). This suggests that a visualisation should contain all the information the viewer requires to understand what is being shown, without needing further explanation. Ultimately, a visualisation should not be placed as a stand-alone effort to inform, rather one step towards an holistic communicative process. Therefore how spatial data are visualised is crucial to how they are applied in a social context and needs careful consideration. There has been recognition that scenarios using spatial data are not well suited to dealing with local landscapes (Munday, Jones et al. 2010) and visualising a regional perspective is required. But there is still a lack of studies which deal with local level change in three dimensions (Munday, Jones et al. 2010).

The following sections breakdown the processing stages of creating a visualisation from the meshed point data using software designed for graphical three-dimensional visualisation (3DS Max, students autodesk, version 2011) and discuss some of the issues that are raised in the broader context of communicating a climate scenario and uncertainty. If the ultimate goal of this visualisation is to play a role in an holistic communicative process on a local scale, then the creation of a complete model needs to reflect a consideration of all these things.

\subsection{Materials}

After the objects were imported to 3DS Max, textures were applied to create a realistic appearance on the buildings [Fig. 4]. This process was time-consuming and required attention to detail. The 'material' editor in 3DS Max was used to control which textures were applied and to which object, but a UVW map (the letters $\mathrm{U}, \mathrm{V}, \mathrm{W}$ being graphical replacements for $\mathrm{X}, \mathrm{Y}$, $\mathrm{Z}$ of the original 3D model) had to first be developed in order to correctly place a texture on an object in the scene. UVW maps apply co-ordinates to 2-dimensional images, and act similarly to a Cartesian coordinate system. The third dimension of UVW maps allow them to respond to irregular topography of surface objects. Each object can have one or many textures applied to 
do, but UVW maps have to correspond to the correct map channel in order to be applied correctly. 3DS Max is uniquely suited to generating complex visualisations because it allows several textures to be applied to a single object.

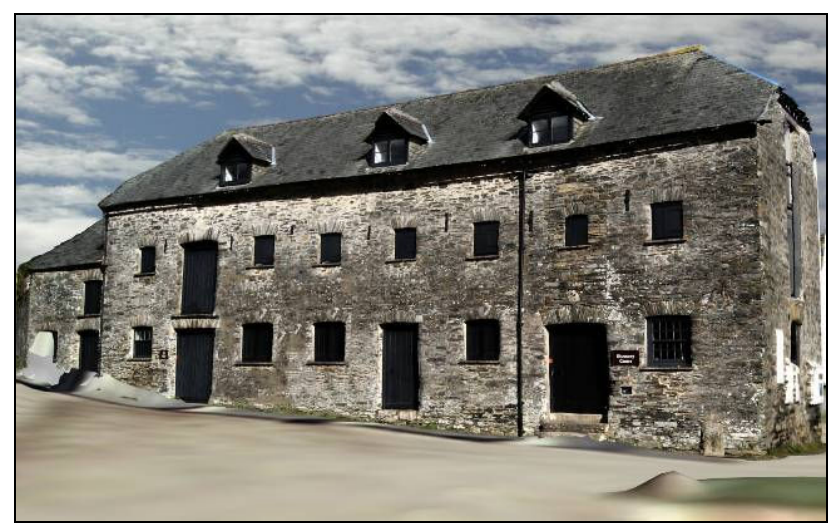

Figure 4 A rendered image of the Discovery Centre, Cotehel Quay, $3 D S$ Max

\subsection{Representing climate scenarios in 3DS Max}

In most climate science communication, scenarios are presented that represent extremes of probability for different climatic extremes. Climate scenarios are defined by UKCP (2009, glossary) as "a description of a plausible future state which is not associated with an ascribed likelihood". Scenarios are therefore an interpretation of events and climates that may occur at a particular site. For the purpose of pilot visualisations in this paper, scenarios were kept to the simplest possible, beginning with a basic tidal flow model showing water movements across the site during a typical tidal cycle. The selection of scenarios that will be used later on in the project will involve stakeholders from a Working Group (WG) comprising key decision-makers in the Tamar Valley (including the UK Environment Agency, AONB, Tamar Estuaries Consultative Forum (TECF), Natural England and Royal Haskoning). Feedback from these meetings has suggested the advantage of visualising scenarios that compare current average high and low tidal water cycles and with future mean high and low water, based on increased sealevel projections. The scenarios represented in the visualisations will be projections of tidal flooding based on a combination of factors; anticipated SLR, low pressure systems, southerly winds and increased precipitation. This is a similar approach to that being undertaken by the Dorset Pathfinder Project team. The Shoreline Management Plan (SMP) review used scenarios reaching 100 years into the future (Nicholson-Cole 2007). Exactly how the combinations of these scenarios are played out is currently pending input from a focus group of community residents and businesses.

\subsection{Communicating uncertainty in the visualisations}

How to communicate uncertainty when dealing with spatial datasets is a research field in its own right, let alone communicating climatic uncertainty (Ehlschlaeger, Shortridge et al. 1997). A typology for uncertainty is still under discussion (Thompson, Hetzler et al. 2005), and Jude et al. (2006) suggest that images may have more potential than textual materialto illsutrate uncertainty effectively. Communicating uncertainty deserves more space than is available in this paper, but two options for this are coloured bands of low to high probability or simultaneous running of animations showing low and high probability SLR predictions.

\subsection{Animation}

3DS Max was used to create the initial animation generating .jpg images for each snapshot of a short movie. These .jpg snapshots were then edited into a short visualisation using QuickTime Pro (version 7.6.6, Apple, California USA), which will be demonstrated in the oral paper delivered at the conference. The initial study has focused on creating a simple scene using a wide-angle, target camera and daylight lighting techniques. The rise and fall of mean water heights for a chosen date in the past and future were rendered. A pilot visualisation included 1800 frames at 30 frames per second, the output being a one minute visualisation. This is the standard frame rate per second for animations the National Television System Committee (NTSC). Each camera shot is a uniquely rendered consecutive image, and the resultant 1800 individual .jpg files are saved to a separate folder. On a standard desktop computer (2.20GHz, 4GB RAM, 32-bit) this process took approximately 72 hours, but is variable dependent on the rendering settings used, computer capabilities, and number of polygons in a scene. In this case, a cluster of computers was used to generate the rendered stills which significantly decreased the rendering time. It is from the rendered .jpg files that QuickTime Pro was used to make the animation (output of .mp4 or .mov file format).

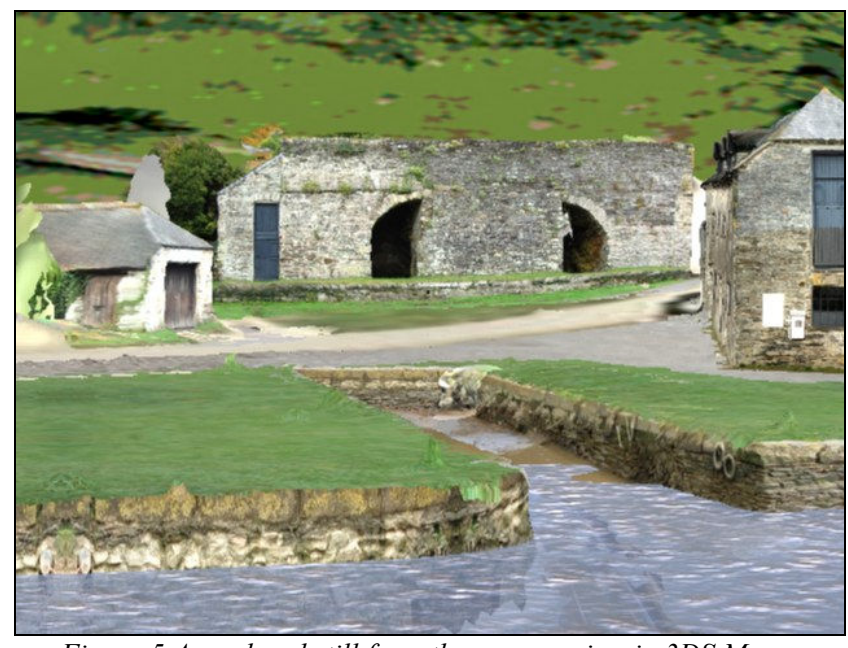

Figure 5 A rendered still from the camera view in $3 D S$ Max

\section{WORKFLOW}

This paper has shown a robust workflow for visualising multiscale spatial data generated by laser scanning devices. Figure 6 is a conceptual model summarising key stages in this workflow. 


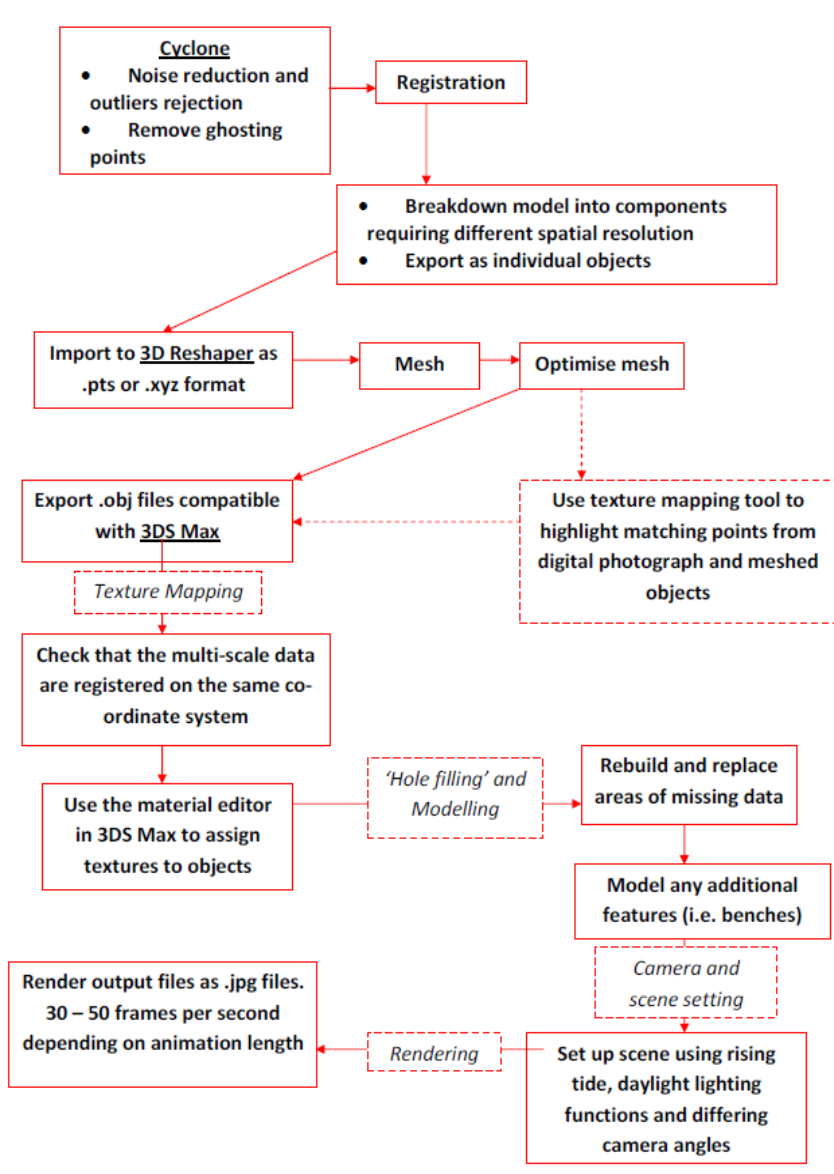

Figure 6 Workflow showing processing stages

\section{DISCUSSION}

This section analyses the methods used in this paper, and seeks to broaden the research to consider some of the complexities involved in balancing photo-realism and data accuracy. Depending on the application of these visualisations, these two concepts (accuracy and photo-realism) can be misleading for the audience of the final visualisation.

A significant problem when discussing accuracy is that error can propagate as the data are processed, and although initial scanning at a dense spatial resolution may appear to provide a more complete dataset, this can be problematic further in the workflow. High density point clouds create significant processing issues if the data are to be meshed in order to generate a digital elevation model (DEM). As Pieraccini et al. (2001) explain a noisy point cloud can disrupt the mesh creating larger inaccuracies in the dataset than previously captured. This is clearly dependent on the size and framework of the mesh. Maximising the number of triangles in a mesh, and thereby increasing the level of spatial detail is often considered advantageous in some settings. It is important, however to recognise that there are trade-offs here, specifically related to data accuracy. Firstly, accuracy is reduced if the number of triangles in the mesh is reduced. This is because it results in an increasing level of interpolation between data points. Secondly, accuracy can be improved with an increasing mesh size because fewer extremes are generated from outlying data. In most cases increasing the density of the mesh will provide a more realistic texture to a surface, but these examples tend to be close-range scanning of artefacts (Dekeyser, Gaspard et al. 2002). Although
Dekeyser et al. (2002) argue for accuracy in the field of cultural heritage documentation, the focus on digitizing heritage for conservation work may not require the same consideration as that for providing visualisations based on projections of climate change, especially for the use of TLS on landscape scale studies. This paper shows that a compromise can be made between accuracy and realism in visualisation of $3 \mathrm{D}$ landscapes. To meet accuracy requirements established from the documentation of cultural artefacts, it is possible to separate individual objects of point cloud data. In the later stages of processing and visualisation, the geo-rectified datasets can easily be united to make a complete, realistic looking model at varying mesh densities across varying spatial scales.

\section{CONCLUSIONS}

This paper has shown how TLS and LIDAR can be used within a visualisation framework for photorealistic visualisations of future climate impacts at heritage sites. The impact of sea-level rise driven by climate change will affect heritage sites globally, and research efforts can be developed to communicate changes and visualise future threats, such as flooding. In particular this paper has demonstrated a workflow from data acquisition to visualisation, which meets the need for accurate and realistic models that to be applied in public engagement contexts. The paper has presented a detailed breakdown of the processes involved to mesh, texture and animate a $3 \mathrm{D}$ scene, taking into consideration accuracy and realism requirements. The multiscale data sources used in this approach provide a regional to local scale which meets a need for local level climate change communication. The introduction of a hydrological flood model would further the potential applications of these 3D visualisations.

\section{ACKNOWLEDGEMENTS}

This project is funded by a scholarship from the European Social Fund, supported with a bursary from the National Trust. Thanks go to Toby Fox and Joe Lawrence at Cotehele for access and co-operation during scanning.

\section{REFERENCES}

Adger, W. N., N. W. Arnell, et al. 2005. "Successful adaptation to climate change across scales." Global Environmental Change 15 pp: $77-86$.

Ahmad, Y,. 2006. "The scope and definitions of heritage: from tangible to intangible" International Journal of Heritage Studies 12(3), pp. 292-300

Anderson, K., Bennie. J., Wetheralt, A. 2010. "Laser scanning of fine scale pattern along a hydrological gradient in a peatland ecosystem". Landscape Ecology, 25(3), pp. 477-492.

Barber 2003. "Towards a standard specification for terrestrial laser scanning". International Archives of Photogrammetry and Remote Sensing XXXIV-5/C15 pp. 619-624.

Brenner, C., C. Dold, et al. (2008). "Coarse orientation of terrestrial laser scans in urban environments." ISPRS Journal of Photogrammetry and Remote Sensing 63(1) pp. 4-18. 
Cassar, M. 2005 "Climate change and the historic environment". Centre for Sustainable Heritage, University College London: London, UK.

Cassar, M., Pender, R. 2005 "The impact of climate change on cultural heritage: evidence and response". $14^{\text {th }}$ Triennial Meeting The Hague Preprints, Centre for Sustainable Heritage, University College London. pp. 610-616

CCPL 1995. "Portland Bill to Rame Head." Shoreline Management Plan: Sub-cells 6a, 6b \& 6c. http://www.ciscag.org/smp1 filesindex.html\#south (accessed 7 Feb. 2011)

DEFRA 2010. "Climate change plan 2010" http://www.defra.gov.uk/environment/climate/documents/climat e-change-plan-2010.pdf. (accessed 13 Nov. 2009)

Dekeyser, F., F. Gaspard, et al. 2002. "Cultural heritage recording with laser scanning computer vision and exploitation of architectural rules." The International Archives of the Photogrammetry, Remote Sensing and Spatial Information Sciences XXXIV(5/W12).

DeSilvey, C. In press. "Making sense of transience: an anticipatory history" Cultural Geographies

Ehlschlaeger, C. R., A. M. Shortridge, et al. 1997. "Visualizing spatial data uncertainty using animation". Computers \& Geosciences 23(4), pp. 387-395.

Entwistle, J. A., K. J. W. McCaffrey, et al. 2009. "Three dimensional (3D) visualisation: the application of terrestrial laser scanning in the investigation of historical Scottish farming townships." Journal of Archaeological Science 36(3) pp. 860866.

Flatman, J. 2009. “A Climate of Fear: Recent British Policy and Management of Coastal Heritage" Public Archaeology 8(1), pp. 3-19

IPCC, 2007. Summary for Policymakers. In: Climate Change 2007: The Physical Science Basis. Contribution of Working Group I to the Fourth Assessment Report of the Intergovernmental Panel on Climate Change, Cambridge University Press, Cambridge.

Jenkins, G. J., J. M. Murphy, et al. 2009. "UK Climate Projections: Briefing report." (Met Office Hadley Centre, Exeter, UK).

Jude, S., A. P. Jones, et al. 2006. "Visualisation for Participatory Coastal Zone Management: A Case Study of the Norfolk Coast, England." Journal of Coastal Research 22(6) pp. 1527-1538.

Leica 2010. "Leica HDS3000 versatile, high-accuracy 3D laser scanner. Product Specifications”. http://www.leicageosystems.com/media/new/product_solution/Leica_HDS3000. pdf. (accessed 22 Jun 2009)

Munday, P., A. Jones, et al. 2010. "Utilising scenarios to facilitate multi-objective land use modelling for Broadland, UK to 2100." Transactions in GIS 14(3) pp. 241-263.
Nagihara, S., K. R. Mulligan, et al. 2004. "Use of a threedimensional laser scanner to digitally capture the topography of sand dunes in high spatial resolution." Earth Surface Processes and Landforms 29(3) pp. 391-398.

NationalTrust. 2005. Shifting Shores - living with a changing coastline. Shifting Shores. National Trust. http://www.nationaltrust.org.uk/main/w-shifting_shores.pdf. (accessed 21 Sep. 2009)

NationalTrust. (2010). "Going local, fresh tracks down old roads: our strategy for the next decade." http://www.nationaltrust.org.uk/main/w-strategy-next-decade17-march.pdf (accessed 1 Sep. 2010)

Natural England. 2008. "State of the environment" http://naturalengland.etraderstores.com/NaturalEnglandShop/N E85 (accessed 7 Feb 2011)

Nicholson-Cole, S,. O'Riordan,. T. 2009. "Adaptive governance for a changing coastline: science, policy and the public in search of a sustainable future" in Adger, N.W., Lorenzoni, I. and O'Brien, K., (eds.) Adapting to climate change: thresholds, values, governance. Cambridge University Press, Cambridge

Pieraccini, M., G. Guidi, et al. 2001. "3D digitizing of cultural heritage”. Journal of Cultural Heritage 2 pp. 63-70.

Schulz, T. and H. Ingensand 2004. "Terrestrial laser scanning investigations and applications for high precison scanning. http://www.fig.net/pub/athens/papers/ts26/TS26_1_Schulz_Ing ensand.pdf." FIG Working Week. Athens, Greece. May 22-27

Thompson, J., B. Hetzler, et al. 2005. "A typology for visualising uncertainty". Conference on visualisation and data analysis. San Jose, CA. USA.

Tunbridge, J. and G. J. Ashworth, Eds. 1996. Dissonant heritage: the management of the past as a resource in conflict. Chichester, New York, J. Whiley.

Zhilin, L., J. Chen, et al., Eds. (2008). Advances in photogrammetry, remote sensing and spatial information sciences: 2008 ISPRS congress book, CRC Press, New York. 